\title{
Low Grade Central Osteosarcoma
}

National Cancer Institute

\section{Source}

National Cancer Institute. Low Grade Central Osteosarcoma. NCI Thesaurus. Code C6474.

A low grade osteosarcoma arising from the medullary portion of the bone. It affects the long bones and is characterized by the presence of fibroblastic stroma and osteoid production. Pain and swelling are the usual sign and symptom. The prognosis is more favorable than conventional osteosarcoma. 